\section{Tin......................... The two faces of consciousness}

\author{
Consciousness: An Introduction \\ by Susan Blackmore \\ Hodder and Stoughton: 2003. 544 pp. £19.99 \\ Oxford University Press: 2003. 460 pp. \\ \$39.95 (pbk), \$79 (hbk)

\section{Ilya Farber}

The study of consciousness being rather broad, its more science-oriented practitioners quickly become adept at glancing through promising-looking new books to discern whether they partake a little too much of the 'cosmic'. This isn't usually difficult, but Susan Blackmore's new book almost seems to have been intentionally designed to thwart such attempts at classification. Consciousness: An Introduction is clearly intended and marketed as a collegelevel textbook, but it sports a cover that is dominated by a glowing humanoid outline festooned with chakra-like circles and reaching ecstatically towards some sort of celestial radiance.

A glance through the copious figures initially reveals a reassuring profusion of brains and graphs and experimental protocols, but in the final quarter of the book these give way to buddhas, drug-induced visions and floating spirits. Even the usually reliable strategy of investigating the author's credentials just generates new puzzles. A search through Blackmore's oeuvre turns up near-death experiences and memes, a book on testing your psychic powers and a chapter on why parapsychology tells us nothing about consciousness. For decades she described herself as a hopeful and open-minded investigator of psychic phenomena, but was all the while on the board of the magazine Skeptical Inquirer, and in 2001 she announced the end of her involvement in such studies. It is easy to imagine potential readers or teachers giving up in bafflement, unable to figure out just what kind of book this is.

That would be a shame, though, because Blackmore has in fact written a truly excellent textbook. Two years ago she gave up her university position to work on this project full-time, and the attention shows. The book's 27 detailed chapters cover every major aspect of consciousness, and Blackmore reveals herself to be a careful and judicious researcher: the central figures and theories of most chapters are familiar, but they are presented with unusually careful attention to details of argumentation and evidence, rather than being reduced to the sort of simple iconic positions that fuel most 'battle of ideas' texts. Many lesser-known authors and positions are also introduced, and some of the most interesting ones receive extended treatment. The book is nearly encyclopaedic

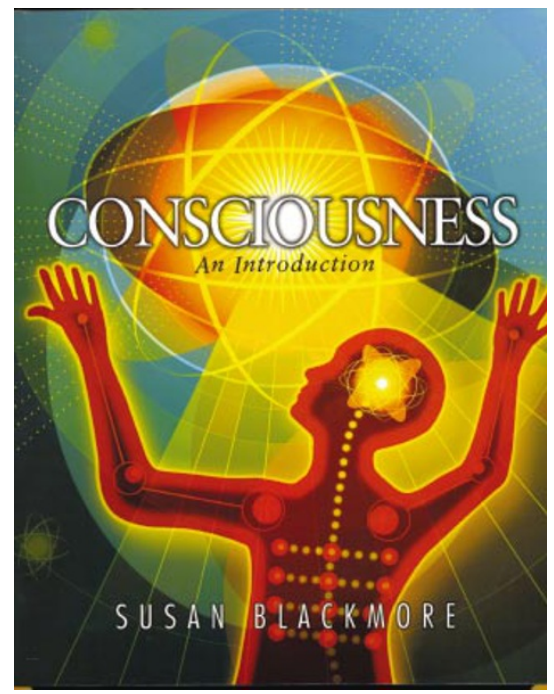

Books about consciousness divide into the scientific and the 'cosmic' - but which is this?

in its comprehensiveness, but the discussion is carefully structured: ideas appear not as individual items to be memorized, but as steps in an integrated, multifaceted process of investigation.

The book does have a bit of a split personality, seeming at times like a guidebook to self-discovery and at others like a primer on recondite academic disputes. It soon becomes clear, however, that this bipolar character is strategic. The chattier bits (full of second-person questions and exhortations) provide excitement and motivation, and encourage students to adopt an engaged, reflective approach to the material, whereas the more scholarly parts delve unapologetically and at length into the details of particular theories and problems. This double structure should make the book accessible and attractive to a wide range of readers.

There are a few notable problems. One is an unfortunate tendency for favourite authors, such as Daniel Dennett and Benjamin Libet, to crop up again and again in different contexts, sometimes in place of others who would arguably be more relevant. Blackmore draws on a wide variety of philosophically engaged scientists (including Francis Crick, Antonio Damasio, Ray Jackendoff, Vilayanur Ramachandran and Francisco Varela), but is much less careful with scientifically engaged philosophers, often letting Dennett stand in for the whole pack. This is most problematic in the chapters on neuroscience, where one would have liked to see more coverage of the specific proposals of philosophers who specialize in the topic, such as Patricia and Paul Churchland, Kathleen Akins, Ned Block, Owen Flanagan and Thomas Metzinger. Blackmore, an experienced author of popular-science books, often uses the journalist's technique of using individual scholars as symbolic representatives of broader positions, a practice that is less appropriate in the academic context and only exacerbates the above problems. The later chapters on parapsychology, hallucinatory states and meditative spiritual traditions are also less successful than the rest; Blackmore's combination of expertise and scepticism makes her an ideal 'tour guide' for such realms, but ultimately these chapters establish little and do not seem to connect with the ideas developed in the earlier sections.

Ultimately, this remains a very satisfying book. It could serve well as a core text for courses in philosophy, psychology and related disciplines, and would provide useful context for other, more discipline-specific texts. Its broad scope and clear explanations also make it an excellent choice for independent study. It's a shame about the cover, though. This might seem a petty complaint, but considering that academic respect for the study of consciousness is still grudging and probational, such matters of appearance are not trivial. I'll be using Consciousness in my course next semester, but I'll also be passing out a nice selection of book covers on the first day of class.

Ilya Farber is in the Department of Philosophy, George Washington University,

Washington DC 20052, USA

\section{$\bullet$ Rich rewards}

\section{Pioneers of Microbiology and the} Nobel Prize

by Ulf Lagerkvist

World Scientific: 2003. 182 pp. \$24, £16

\section{W. F. Bynum}

Historians of twentieth-century science often write about their subject in terms of Nobel milestones. Laureates are convenient markers of major scientific advance, and have the added attraction that a great deal of information about them is generally in the public domain. This in itself reinforces their scientific visibility and assures us that, on the whole, the various bodies that Alfred Nobel asked to adjudicate his prizes have done their job correctly. Disciplines such as mathematics, evolutionary biology and geology, overlooked by Nobel, have their own means of rewarding excellence, and historians use these accordingly.

That scientists also value the award of the ultimate scientific prize far beyond its considerable monetary value has recently been demonstrated by the contested 2003 prize for medicine or physiology, which was awarded for medical magnetic resonance imaging (see Nature 425, 648; 2003). Although it took some time for the current prestige of the Nobel prizes to develop, the second award in physiology or medicine (1902) exacerbated a priority dispute between 


\section{Winging it}

The colour and intricate detail of a moth's wing, like the one shown here from the painted lichen moth (Hypoprepia fucosa), is rarely appreciated. Although there are many more species of moths than butterflies, their nocturnal habit tends to keep them from view. Print-maker Joseph Scheer became interested in moths when he began using a high-resolution scanner to capture directly images of insects. The prints allow a view of the anatomical detail, previously only available through a stereomicroscope, across an entire specimen. Now Scheer has become something of an amateur lepidopterist, studying the diversity of the local moth populations as he collects more specimens for his prints, a selection of which can be seen in Night Visions: The Secret Designs of Moths (Prestel, £29.95).

Mary Purton

Ronald Ross (who got the prize) and Giovanni Battista Grassi (who was overlooked) over their relative contributions to knowledge of the role of Anopheles mosquitoes in malaria transmission. Nobel had made provision for each of his prizes to be shared by up to three people, although shared prizes in science were rare before the inter-war period and became the norm only after the Second World War.

Ulf Lagerkvist's discussion of the early medicine or physiology prizes is by far the most original part of his little book, which focuses on the lives of four pioneers of microbiology who all won the coveted prize: Emil von Behring, Robert Koch, Paul Ehrlich and Elie Metchnikoff. He describes the composition and deliberations of the early committees of the Karolinska Institute, the institution charged by Nobel with choosing the laureate in that loosely defined area. Johan

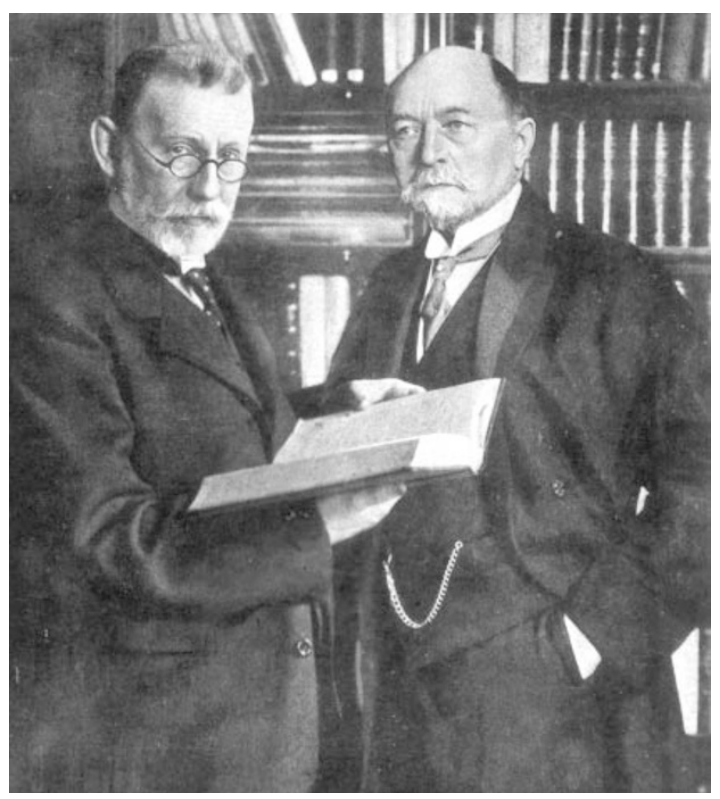

Nobel prizewinners: Paul Ehrlich (left) and Emil von Behring.

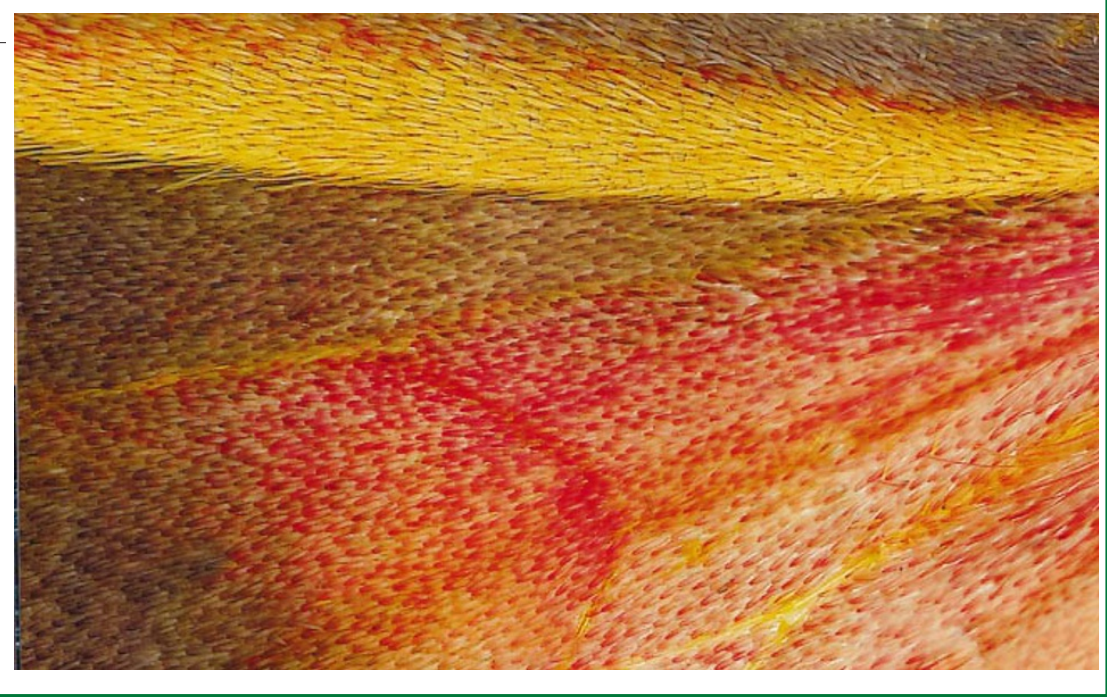

Erik Johannson, professor of physiology at the Karolinska, probably persuaded Nobel to add 'physiology' to the medical prize. Johannson campaigned ardently against the award of a prize to Paul Ehrlich, his reason being that Ehrlich's famous 'side-chain' theory of antigen-antibody interaction was too speculative and had been contested by Svante Arrhenius, the deserving winner of the 1903 prize for chemistry.

Grumblings about nationalistic bias surfaced early in international attitudes towards Nobel committees, and it must be said that the first two Scandinavian medical laureates, Niels Finsen (1903) and Allvar Gullstrand (1911), have not exactly remained household names, if they ever were. Johannson may have been unusual in raising the Scandinavian issue, and the internationalism of the early prizes is evident in all the sciences. The medical committee was also adventurous in how it shared a couple of early prizes. Two of Lagerkvist's four principals - Ehrlich and Metchnikoff — split the 1908 prize, and the committee had already divided the 1906 prize between Camillo Golgi and Santiago Ramón y Cajal. In both cases, the recipients held diametrically opposed views on their research areas, Golgi and Ramón y Cajal publicly disputing the structure and function of neuronal elements. Ehrlich and Metchnikoff represented chemical and cellular approaches to the main determinants of immunity. In contrast, the early shared physics prizes went to people who had worked together, and the chemistry committee did not award a shared prize until 1929.

The other awkwardness that had to be resolved before the first awards was Nobel's stipulation that the science prizes ought to be awarded for the best research 'in the preceding year'. Members of the awarding bodies knew that it takes time for the permanent value of a scientific discovery to be judged, and one of Nobel's original trustees, Ragnar Sohlman, managed to get the terms of the will relaxed. The Medicine or Physiology Committee seemed to have adopted a rough ten-year guideline, which explains why some of the early recipients were deemed eligible. Thus the first winner, von Behring, had done his important work on diphtheria (the word is irritatingly misspelled throughout Lagerkvist's book) roughly a decade earlier. By the time of the award he was engaged in largely fruitless research on tuberculosis.

Few would quibble with the decision to crown each of Lagerkvist's four pioneers. From the historical perspective, however, even the informal ten-year rule of the Committee creates problems. Koch was a giant of bacteriology in the 1870s and 1880s, but his later years, with tuberculin, the radical distinctiveness of bovine and human tuberculosis, and the wanderings in Africa investigating tropical diseases, did not produce the stuff of greatness. By 1908, when Metchnikoff received his prize, he was more obsessed with intestinal hygiene and longevity than with basic immunology. Only Ehrlich remained unremittingly dedicated to his laboratory craft.

Some of these issues have to be teased out of Lagerkvist's volume, which tries to do too much in too little space. The first half, a potted biographical history of medicine, has been done many times before, and should have been omitted in favour of a more extensive and subtle examination of the achievements and careers of his four principals, each of whom left permanent legacies.

W. F. Bynum is at the Wellcome Trust Centre for the History of Medicine, University College London, 24 Eversholt Street, London NW1 1AD, UK. 